\title{
Zirconium-89 labelled rituximab PET-CT imaging of Graves' orbitopathy
}

\author{
Bart de Keizer ${ }^{1}$ (D) Kamil G. Laban ${ }^{2,3}$ (D) Rachel Kalmann $^{2}$ (D)
}

Received: 21 August 2019 / Accepted: 4 November 2019 / Published online: 18 November 2019

(C) The Author(s) 2019

\section{Zirconium-89 labelled rituximab PET-CT imaging of Graves' orbitopathy}

Graves' orbitopathy (GO) is the main extrathyroidal manifestation of Graves' disease. A proportion of patients have moderate to severe orbital inflammation, with corneal ulceration, intense pain or even compressive optic neuropathy [1]. Highdose glucocorticoids (GCs) are the first-line treatment in these patients. When high-dose GCs fail to reduce the inflammation, shared decision-making is recommended for selecting a second-line treatment. Options for treatment include a second course of intravenous GCs, oral GCs combined with orbital radiotherapy, rituximab or watchful waiting [2]. Rituximab treatment is not yet approved for clinical use in $\mathrm{GO}$ and roughly $50 \%$ do not have significant improvement 1 year after treatment [3]. In rheumatoid arthritis, zirconium-89-labelled rituximab ( ${ }^{89} \mathrm{Zr}$-rituximab) PET-CT shows promising clinical value with higher rates of response to therapy in patients with higher ${ }^{89} \mathrm{Zr}$-rituximab uptake in responders than in non-responders
[4]. ${ }^{89}$ Zr-rituximab PET scanning is approved by Dutch authorities to select patients for rituximab treatment and is used in our hospital to select patients with orbital inflammatory disease (including GO) that might benefit from rituximab treatment. In a recent retrospective study, we showed that of 4 patients with intense ${ }^{89} \mathrm{Zr}$-rituximab uptake in orbital inflammatory disease, 3 patients responded well to rituximab treatment [5]. Here, we present a patient with GO refractory to intravenous GCs. PET-CT performed 3 days after $74 \mathrm{MBq}$ ${ }^{89} \mathrm{Zr}$-rituximab showed high uptake in orbital musculature. ${ }^{89} \mathrm{Zr}$-rituximab binding more than in normal bone marrow and comparable to binding in normal lymph nodes was observed in thickened medial rectus muscle of the left eye (SUVmax 5.9) and the superior rectus muscle of the right eye (SUVmax 5.2) (Figure 1 A coronal CT reconstruction, B coronal PET-CT reconstruction, $\mathrm{C}$ axial PET-CT reconstruction of right superior rectus muscle and D axial PET-CT reconstruction of left medial rectus muscle). Because of high ${ }^{89} \mathrm{Zr}$-rituximab uptake, rituximab treatment was initiated.

This article is part of the Topical Collection on Image of the month.

Bart de Keizer

b.dekeizer@umcutrecht.nl

1 Department of Radiology and Nuclear Medicine, University Medical Center Utrecht, University Utrecht, Heidelberglaan 100, 3584, CX Utrecht, The Netherlands

2 Department of Ophthalmology, University Medical Center Utrecht, University Utrecht, Utrecht, The Netherlands

3 Laboratory of Translational Immunology, University Medical Center Utrecht, University Utrecht, Utrecht, The Netherlands 
Figure 1
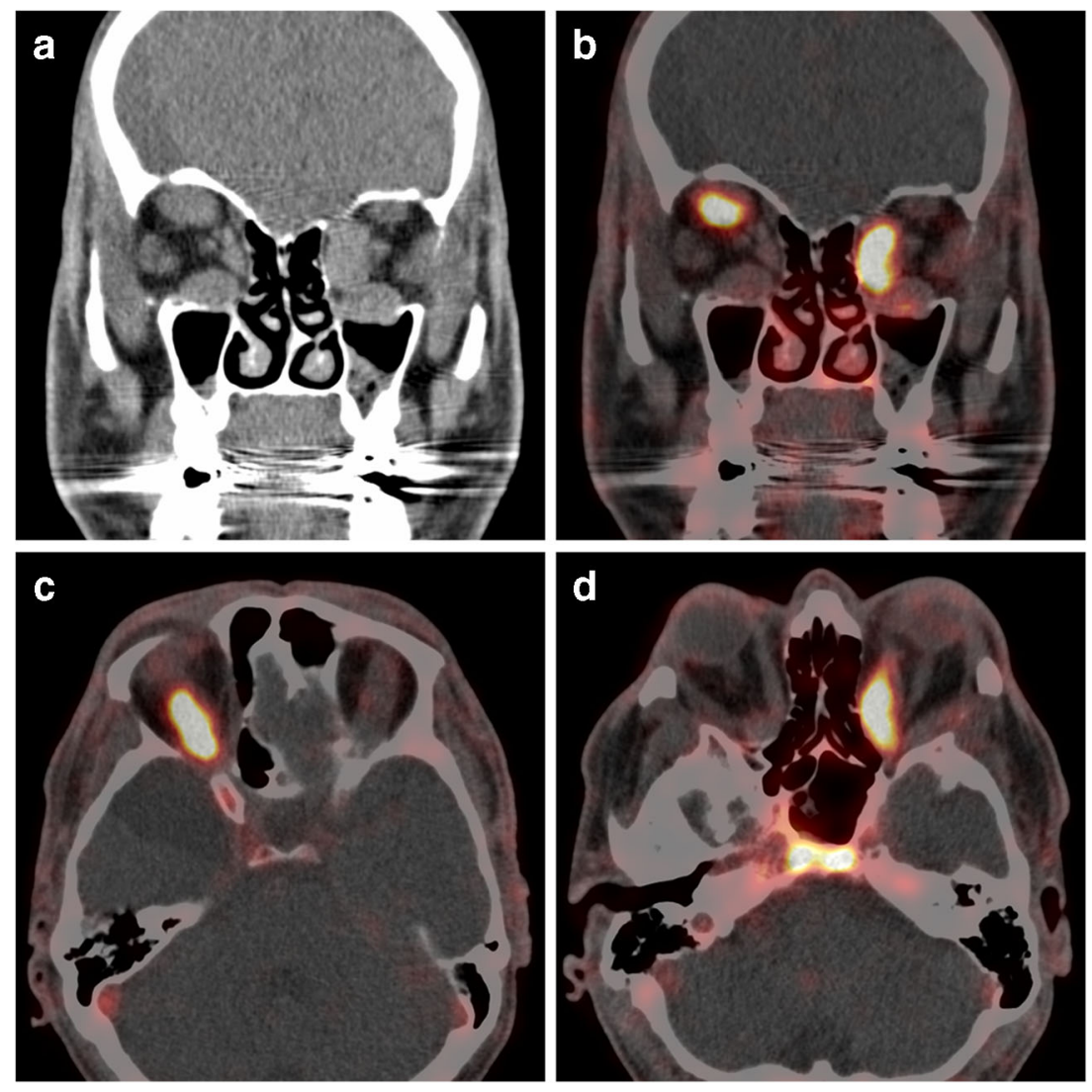

Compliance with Ethical Standards The authors declare that they have no conflicts of interest.

All procedures performed in studies involving human participants were in accordance with the ethical standards of the institutional and/or national research committee and with the 1964 Helsinki declaration and its later amendments or comparable ethical standards.

Informed consent was obtained from the participant included in the study.

Open Access This article is distributed under the terms of the Creative Commons Attribution 4.0 International License (http:// creativecommons.org/licenses/by/4.0/), which permits unrestricted use, distribution, and reproduction in any medium, provided you give appropriate credit to the original author(s) and the source, provide a link to the Creative Commons license, and indicate if changes were made.

\section{References}

1. Bahn RS. Graves' ophthalmopathy. N Engl J Med [Internet]. 2010;362:726-38 Available from: http://www.ncbi.nlm.nih.gov/ pubmed/20181974.
2. Bartalena L, Baldeschi L, Boboridis K, Eckstein A, Kahaly GJ, Marcocci C, et al. The 2016 European Thyroid Association/ European Group on Graves' Orbitopathy Guidelines for the Management of Graves' Orbitopathy. Eur Thyroid J [Internet]. 2016;5:9-26 Available from: https://www.karger.com/Article/ FullText/443828.

3. Stan MN, Garrity JA, Leon BGC, Prabin T, Bradley EA, Bahn RS. Randomized controlled trial of rituximab in patients with Graves' orbitopathy. J Clin Endocrinol Metab. 2015;100:432-41.

4. Bruijnen S, Tsang-A-Sjoe M, Raterman H, Ramwadhdoebe T, Vugts D, van Dongen G, et al. B-cell imaging with zirconium-89 labelled rituximab PET-CT at baseline is associated with therapeutic response 24 weeks after initiation of rituximab treatment in rheumatoid arthritis patients. Arthritis Res Ther. 2016:18 Available from: http://www. ncbi.nlm.nih.gov/pubmed/27863504.

5. Laban KG, Kalmann R, Leguit RJ, de Keizer B. Zirconium-89labelled rituximab PET-CT in orbital inflammatory disease. EJNMMI Res. 2019;9:69. https://doi.org/10.1186/s13550-0190530-9.

Publisher's note Springer Nature remains neutral with regard to jurisdictional claims in published maps and institutional affiliations. 